\title{
Between power and perception: Understanding youth perspectives in participatory monitoring and evaluation (PM\&E) in Ghana
}

\author{
Evans Sakyi Boadu*, Isioma Ile \\ School of Government, University of the Western Cape, South Africa
}

\section{A R T I C L E I N F O}

\section{Keywords:}

Evaluation

Implementation

Participatory

Monitoring

Stakeholders

Youth

\begin{abstract}
A B S T R A C T
Participatory monitoring and evaluation (PM\&E) approaches have been touted as an important concept for local participation in social interventions programmes. Utilizing a process analysis approaches, the PM\&E data gathered through key informant interviews, formal surveys, and policy frameworks were analyzed. The study revealed three dominant power struggles between youth and programme implementers in three districts at the Greater Accra region, Ghana. The first and pervasive form of power dynamics involves the youth and programme implementers. The second involves a variety of arrangements with the government on one hand and implementers and youth on the other side. The third is who qualifies to be a beneficiary and for that matter participate in the PM\&E. In these three forms of power struggles the paper reveals superior implementers control of who participate in the programme PM\&E and at what stage in the process. The power imbalance between programme implementer and target beneficiaries impeded the level of beneficiaries' participation in the PM\&E.
\end{abstract}

\section{Introduction}

A people-centred approach to social intervention programmes has been espoused by many scholarships in the development literature (Antonio, 2001; Hogh-Jensen, Oelofse, \& Egelyng, 2010). It is often premised on the assumption that the objectives of such intervention programmes are better maximized when beneficiaries actively involved in every facet of the programme. The dilemma on the part of government programme implementers, donors and development agencies is to ensure that the intervention programme produces efficient and effective outcomes. The success or otherwise has mostly been alluded to the active participation of the various stakeholders from the decisionmaking stage through implementation to impact evaluation. Parfitt (2004) argued that development projects/programme are likely not to achieve their intended goals if the programme target individuals or communities are left out in the planning, design, implementation and monitoring and evaluation.

A cursory search into the literature revealed some degree of scepticism on the part of government programme implementers to involve young people in the development process such as participatory monitoring and evaluation (PM\&E) (Boadu \& Ile, 2017). In support of Boadu and Ile (2017) argument, Zeldin, McDaniel, Topitzes, and Calvert, (2000) asserts that development partners, programme implementers and donors fail to truly integrate youth in the processes leading to a development decision making. The author further argues that the extent to which young people participate in the discussion of programme success or failure is very limited and are far often portrayed as inexperience in matters of such nature. On this score, Holte-McKenzie, Forde, and Theobald (2006) posited that the power dynamics between government programme implementers and target beneficiaries have the potential to influence the latitude of participation. Certainly, it would seem rational to discourse that the active involvement of programme beneficiaries in the PM\&E activities are key to the success of such an intervention programme.

Mosse (2005) educates us that the power differentials between the programme stakeholders and implementers have a great impact on the level of participation in the PM\&E activities. Although the concept of PM\&E has been loosely defined, there are some agreeable tenets among scholars that cannot be ignored. The approaches and methods may differ but the active participation of primary stakeholders is of great importance to the programme implementers, donors and development agencies (Hilhorst \& Guijt, 2006, pp. 4). Cognizant of this important fact, it is necessary to note that there are varying classifications and typologies of participation as an approach of evaluation. Intriguingly, the stage(s) in which programme beneficiaries are permitted to participate in the evaluation process is usually determined by programme implementers, donors and development partners to the detriment of the primary stakeholders (Zeldin et al., 2000). Boadu and Ile (2018)

\footnotetext{
* Corresponding author.

E-mail addresses: 3616746@myuwc.ac.za (E.S. Boadu), iile@uwc.ac.za (I. Ile)
} 
affirmed that the extent to which target beneficiaries are allowed to participate in the evaluation activities is sometimes dependent on the available financial and material resources.

Pimbert and Pretty (1995) argued that there are seven typologies of participation which is hierarchical nature. From below is the passive participation; participation in information giving; participation by consultation; participation for material incentives; functional participation; interactive participation; and self-mobilization (Pimbert \& Pretty, 1995: 26). The authors argued that the passive participatory approach is where the individuals or groups are told by development planners what they intend doing or what has already been done. On the other hand, the interactive participation, the individual is actively integrated or become fully involved in the various activities, from the policy decision-making through to the impact evaluation. However, the ultimate goal is to achieve self- mobilisation which tends to be a challenge in most intervention programmes. It is not my intention here to deal extensively with these typologies of participation except to point out that there are forms and levels of participation which can influence the conduct of PM\&E in a youth intervention programme.

The goal of this paper is to explore the power disparities between government policy/programme implementers and target beneficiaries (youth) and its implications on the PM\&E objectives. This is done through a case study of PM\&E within the Local Enterprises and Skills Development Programme (LESDEP) in Ghana. The rest of the paper is structured as follows. Section two provided a literature overview by unpacking the interlocks within and between PM\&E and power (politics) if any. Section three presented an overview of the case study initiative (LESDEP) and research design. Section four critically examined the logic of PM\&E from the perspective of the youth and some pros and cons in the system. The section, before concluding, provided some lessons and alternative approaches for youth participation in PM\&E.

\section{Literature review}

In the quest of ensuring development project effectiveness, practitioners have adopted many approaches; famous among them is the bottom-up approach, with enormous prominence on participatory approaches, whether at the individual, group or community level (Turner, 2007). The need to integrate local people and what they perceive to be their most pressing needs continues to gain weight in many development projects although some development scholars have attributed that to international development agencies and donor's persuasion (Boadu \& Ile, 2017). It is not surprising that local people or programme centered populations (youth) in most development projects are greatly involved not only in the planning or decision-making processes but also have become an integral part of monitoring and evaluation procedures in their (development planners) quest of ensuring good participation (Boadu \& Ile, 2018; Holte-McKenzie et al., 2006). The focus of this review is to unravel the power disparities between project target beneficiaries (youth) and government or implementers.

\subsection{The ambiguity of young peoples' participation in $P M \& E$}

The inclusion of the youth in the political, social and economic life of a country has gained paramountcy in recent times if not all the Post 2015 development agenda (Simon, 2014). Youth participation evolves through a tripartite continuum. First, a conscious effort on the part of youth to initiate development projects of their own picking or preference; second, a deliberate attempt on the part of donors or adults to involve the youth in their interventions; third, the recognition from both group (youth and adults) to work together in partnerships (Checkoway \& Gutierrez, 2006; Zeldin, Petrokubi, \& MacNeil, 2008). The authors hasten to add that the problem is not really about who is leading what, when and how (is it youth-led, adult-led or a partnership between the two) but rather, whether the youth have some influence. However, Holte-McKenzie et al. (2006) and Zurba and Trimble (2014) argued that cultural values and norms can also limit young peoples' active involvement in any participatory approaches.

Young peoples' participation in development interventions seems to confirm or reject the popular parlance attributed to the youth by some social sciences and professional practitioners such as "youth as resources," and it contrasts with that image of "youth as a lost generation" (Checkoway \& Gutierrez, 2006, pp. 2). Young people should have the opportunity to voice out their concerns and offer tangible remedies in any development policies rather than being mere receivers of development interventions perceived by development planners as comprehensive enough to address their problems (Nurick \& Johnson, 2001; World Bank, 2014). Therefore, youth participation in participatory monitoring and evaluation is not misplaced. Involving different stakeholders in participatory approach is key, however, emphasis must be placed on programme beneficiaries in the evaluation activities to ensure that they participate meaningfully which was rightly put as "doing evaluation 'with' and 'by' project beneficiaries rather than 'on' or 'about' them" (Guijt, 2014, pp. 4).

\subsection{Youth, Power and PM\&E}

Youth participation is not just about mere presence, either as human beings or as recipients of development interventions, but rather they must involve control and exertion of influence over institutions and decisions aimed to affect their well-being (Checkoway \& Gutierrez, 2006). Participatory monitoring and evaluation methods have been used in different development interventions. Development planners have adopted the approach for its wider inclusion of stakeholders including young people (Nurick \& Johnson, 2001). The authors further observe that involving project beneficiaries in monitoring and evaluation tends to positively increase their confidence. Youth participation in monitoring and evaluation processes does not only build their confidence in the initiative but also creates "greater sense of project ownership" (see Van-Beers, 2002; Ataov \& Haider, 2006). The integration of young people in the designation of the project right through to the implementation stage does not only improve the project but it also ensures its sustainability (Cahill, 2007; Chouinard \& Cousins, 2013; Department for International Development (DFID, 2010).

Echoing this position, the DFID (2010) maintained that involvement of programme target beneficiaries in monitoring and evaluation tends to produce quality data for further implementation of the project. However, young people need adequate training, skills, knowledge, and support from programme implementers to be able to meaningfully participate in the processes (Cahill, 2007). The literature reveals some level of scepticism on the part of programme implementers and donors in truly involving young people in PM\&E. Young people are mostly portrayed as naïve or inexperienced in matters of such nature (Zeldin et al., 2000). Contrary to the notion that youth involvement in development intervention is the way forward, DFID (2010) sees a bleak in that direction because in most developing countries the youth have very limited influence due to lack of education which deprived them of the needed intellectual skills to participate in public decision making.

\subsection{Relevance and perception of youth participation in $P M \& E$}

Youth participation in project monitoring and evaluation have comprehensively been perceived as the way forward in promoting and supporting several development activities (Tisdall, 2008). The author further argued that it grants the development initiators and donor partners the opportunity to better incorporate the young people in varying stages of decision-making processes, from "micro-scale" within their various societies to the national or international jurisdiction termed as "macro-scales" (Tisdall, 2008, pp.11). However, young people in most countries do not have access to the powers that are, in government, the media and civil society organizations which serve as a limitation for the youth to voice out their concerns (Department for 
International Development (DFID, 2010). Irrespective of this, in instances where they are allowed to participate in the decision-making processes, their contribution is minimal 'one-off consultations' as a result of the weak institutions and complex structures they have to go through (Sabo, 2001). This tends to limit their effort, destroy their confidence and trust in such an evaluation system, hence, the youth inability to actively participate in any development intervention.

In a similar vein, participatory evaluation approach provides a good number of unintended pathways for capacity building in the local actors (youth), community members and programme stakeholders when they are rightfully incorporated by project initiators or planners (Chouinard \& Cousins, 2013). The youth are empowered to acquires evaluation knowledge which put them in a position to greatly access the pros and cons of a government intervention programme (Boadu \& Ile, 2017). The term 'process use' is the nature of these benefits (Patton, 2008) whereas the mere evaluative thinking or learning and system used is acquired by one's nearness to the evaluation systems (Chouinard \& Cousins, 2013). Opposing to the views expressed by the above authors, DFID (2010) discoursed that participatory monitoring and evaluation that involves youth in every aspect of the intervention has been wrongly perceived by most development planners as costly as involving adults. In a similar vein, Shafik (2010) echoing the views by DFID (2010) affirmed that engaging youth in a step-by-step process in every aspect in the life cycle of any social intervention programme such as (planning, design, implementation, and M\&E) will ultimately be a pinnacle for the project effectiveness (Shafik, 2010).

True participatory approach in development projects should entail proper redistribution of power among various stakeholders including young people; a lack of it will ultimately leave the powerless (for instance youth and women) with no voice to influence the processes as well as the outcome of the project (Ackermann, Feeny, Hart, \& Newman, 2003; Lansdown, 2001, Masters, Macintosh, \& Smith, 2004; Shier, 2001). Some scholars have described this kind of participation as "tokenism" and "manipulation" (Arnstein, 1967; Chitukutuku, 2014; World Bank, 2014).

\section{Case study area, design and methods}

A case study approach of inquiry was used for its ability to provide the researcher with a comprehensive understanding of the group or community and their social circumstance to make meaningful observations. The need to examined the special and peculiar conditions in which the subjects under investigation were was key devising some pragmatic solutions. Thus, this section focused on the case study programme and the researched methodology used.

\subsection{Local Enterprise and Skills Development Programme (LESDEP)}

The Local Enterprises and Skills Development Programme (LESDEP) is a national youth-oriented programme implemented through a publicprivate partnership under the auspices of the Ministry of Local Government and Rural Development in partnership with the Ministry of Employment and Social Welfare, Ghana. Other department and organizations such as the National Youth Council (NYC), Ghana Opportunities Industrial Council (OIC) and National Board for Small Scale Industries (NBSSI) as well as Metropolitan, Municipal and District Assemblies (MMDAs) in Ghana (Local Enterprise and Skills Development Programme (LESDEP, 2016). The programme has administrative offices in all the ten regions of Ghana. Having established in October 2010, the programme main goal is to inculcate skills acquisition into the Ghanaian youth; technical or vocational, entrepreneurial and other specialized skills.

The initiative runs fifteen modules which includes, but not, limited to electrician, local garment or fashion designer, beauty care, event organizing or decor, beads making, window or sliding door designer, driving, catering service, fish farming, agro-processing, welding or fabrication, farming, photography, construction and mobile phone repairer (LEADEP, 2016). The programme is open to all the youth in Ghana between the ages of 18 to 35. Ghana has made some strides in its social, economic and political development since the inception of the last republic, 1992. Lessening poverty from $51 \%$ in 1991 to $28.5 \%$ in 2015 , however, the unemployment rate among the youth remains one of the biggest challenges in the country (Amankrah \& Burggraaff, 2012). Therefore, the establishment of an intervention programme such as LESDEP that targets literate or illiterate Ghanaian unemployed youth is a step in the right direction. Ultimately, the programme core mandate is to decrease the unemployment rate among the teeming youth in Ghana.

While the programme chose the term Process Evaluation (PE), however, the term is mostly used interchangeably with PM\&E. I can also be referred to as Participatory Evaluation (PE), Participatory Monitoring (PM), Participatory Assessment, Monitoring and Evaluation (PAME), Stakeholder-based evaluation/Stakeholder Assessment or Empowerment Evaluation (EE) (Estrella, 2000).

\subsection{Design and methodology}

The descriptive analysis and the resulting outcome offered in this paper is a part of a research study conducted in the year 2016 regarding the experience of programme beneficiaries in the PM\&E of Local Enterprise and Skills Development Programme (LESDEP). The research study concentrated on understanding youth experience of the PM\&E and their level of participation in the design and its implementation visà-vis the practitioners and field officers involved in the PM\&E. Data for this paper were collected during the period from August to November 2016. The field study took place in three different districts (La Nkwantanang-Madina Municipality, Ga East District Assembly, and Adenta Municipal Assembly) in the Greater Accra Region, Ghana. These districts were randomly selected out of the sixteen districts in the region. The duality of the research approach focused on unpacking youth involvement in participatory monitoring and evaluation. The following methods of data collection were used;

\subsection{Sampling procedure}

The study focused on different sampling techniques to sample out the population for the individual and in-depth interviews. A simple random sampling was adopted in the selection of respondents out of 500 populations. The stated confidence level was $95 \%$ with a margin of error of $\pm 7.8 \%$. The same method was used to select 3 out of 16 districts in the Greater Accra Region, while purposive sampling was utilized to select officials of the programme for the in-depth interviews.

\subsection{Interviews with youth}

The data was generated through different methods, however, the main approach used was a face-to-face interview with 120 target beneficiaries (youth), 40 from each district. About 43(35.8\%) were females and 77(64.2) males, aged between 18-35 years. The individual interviews on average lasted between $30-45$ minutes and primarily focused on the programme target beneficiaries and their level of participation in the existing monitoring and evaluation activities. Interviews were arranged with each respondent in their place of work which also affected the length of the interview in some cases.

\subsection{Key informant interviews}

Three in-depth interviews were conducted with programme field and monitoring evaluation officials responsible for the progress evaluation design and its implementation in the districts. The key informant interviews with programme field and monitoring and evaluation officials broadly examined issues such as the nature of the existing 
monitoring and evaluation framework, target beneficiary's level of involvement, and pros and cons of beneficiary's participation.

\subsection{Policy frameworks}

The study also focused on other documentation regarding the procedure of monitoring and evaluation to complement the interviews conducted in the field. Utilizing a content analysis approach, the ministerial reports or articles, newspapers, magazines and research papers that have a direct bearing on the study were analysed.

\subsection{Participant observation}

Participant observations approach was also helpful in eliciting some aspect of the qualitative data through a thoroughly noting and recording of the flow of events, the interactions, and information flow and communication channels in the social settings of the beneficiaries and the programme officials. The approach was useful in understanding the different (social, economic, and political) varying power relations between the beneficiaries and programme implementers.

Utilizing a process analysis technique, based on grounded theory (Corbin \& Strauss, 2008), the qualitative data were analyzed to assess the level of beneficiaries' participation and power differentials between implementers and target beneficiaries within the programme progress evaluation activities.

\section{Power, perception and youth participation in PM\&E}

\subsection{The PM\&E perspective of programme implementers}

The field study revealed that PM\&E was included in the designation stage as a model of programme management and in the spirit of the National Youth Employment Programme, which is premised on youth empowerment and inclusive participation in national development agenda. Conversely, implementers tend to have a more pressing issue concerning organizational management as well as the programme implementation than involving the target beneficiaries in the PM\&E. They were engrossed in the programme administration and the provision of apprenticeship job to the beneficiaries who are mostly youth and are in haste of getting a job than to participate in the programme monitoring and evaluation. Although LESDEP is a public-private partnership (PPP), the programme is politically motivated and the pressing issue by the government was to introduce the programme across the length and breadth in the country. It was not surprising that the programme was introduced in all 170 Metropolitan, Municipal District Assemblies (MMDAs) in Ghana in a year to score some political points. The quote below from the in-depth interview is evident that the implementers were more interested in the administrative aspect of the programme than the project process evaluation.

We are interested in investing time and energy in actually getting to know the beneficiaries, the type of apprenticeship job they are interested in, how we can fit that into our limited number of modules [R1, LESDEP staff, November 9, 2016].

The programme was supposed to have field officers in all the districts to assist target beneficiaries to establish their business after training, providing support afterwards and reporting the progress or otherwise to the district or regional secretariat. However, the field study reveals that the officers find it difficult to track beneficiaries using the basic information they provided to their respective district or regional offices. This also affected the reimbursement of the set-up funds provided by the secretariat, which in effect declined the number of youth that was trained in the subsequent years. PM\&E is premised on power, control, cohesion, sharing of knowledge, improving accountability with implementers on one-hand and programme beneficiaries on the other hand. Thus, the failure on the part of the implementers heavily affected the youth participation in the process, which when properly implemented will enhance programme sustainability.

We generally don't use the term PM\&E; we use project evaluation or monitoring. Generally, we do more of progress monitoring of the initiative and impact as well but between the two, the kind, we tend to do more of the progress than the impact because those are the day-to-today assessment of the initiative to see whether we are making any headways in every aspect of the project (LESDEP Staff, November 9, 2016).

The above quote is a good indicator of the fact that the programme had a monitoring and evaluation system. It is evident that PM\&E is difficult to unpack, hence the unlimited terms given to the concept. The quote confirms the challenge that confronts LESDEP staff in distinguishing between monitoring and evaluation, hence the terms was also used interchangeably at LESDEP.

\subsection{The paradox: unravelling $P M \& E$, feedback systems or logical frameworks}

In keeping with the vision of the NYP, shortly after its introduction of the programme in the year 2010, regional and district offices were established for the smooth running of the programme. Moreover, a small group of people was put together across the 170 Metropolitan, Municipal and District Assemblies (MMDAs) in Ghana to monitor the implementation of the intervention programme in their respective districts.

\subsubsection{The assumption of participatory monitoring and evaluation versus programme $P M \& E$}

The structure of the intervention programme as deduced from the field study revealed a hierarchical one with the primary stakeholder at the bottom of the strategical design. From the national coordinators through to the district coordinators as well as other reporting entities within the National, Metropolitan, Municipal and District Assemblies (MMDAs) were exclusively the reserve for programme officials. There is an erroneous connotation of PM\&E approaches as being synonymous with the generation of qualitative data. Estrella (2000, pp. 10) asserted that the concept is not new from conventional monitoring and evaluation-the point of departure is the emphasis on wider stakeholders' participation in the process.

Although LESDEP principles are geared towards 'practical oriented evaluation and assessment' that is premised on well-organized procedures, yet, the programme PM\&E in practice was more rhetoric than as it was prescribed before the commencement of the initiative (the PM\&E was expertly driven in nature and character). The implementers deemed it fit to depend on the field officers or staff in the various districts who are directly connected with the target beneficiaries within the district to the detriment of the primary beneficiary (youth). An approach which deviates from the viewpoints of the proponents of PM\& E (Estrella, 2000).

Assuming the primary stakeholders in the programme worked in tandem with the field officers and senior managers at the various districts, the PM\&E activities would have been more bottom-up emanating from the local level through to the secretariat by ensuring proper accountability and tracking changes. The existing monitoring system would have required beneficiary's associations or representatives working hand in hand with the local field's officers or coordinators by providing support to the field coordinators to collect, collate and analyze the data generated from the field. Unfortunately, the linkages between beneficiaries and the field staff or coordinators were blurry in process.

4.2.2. The assumption of logical frameworks approach versus existing framework

Despite some pitfalls associated with Logical Framework Approach 
(LFA), yet, its purpose for planning, managing and ultimately monitoring of an intervention programme continue to gain some impetus in the development literature since its adoption by USAID in the 1960s (Jacobs, Barnett, \& Ponsford, 2010, pp. 37). Besides, the 'logical framework' with its vertical and horizontal matrixes can unravel intricate social phenomena for a better understanding of the layperson in the monitoring of development programmes.

The programme assumption was that local field coordinates would pass the information collated from the beneficiaries to the Metropolitan, Municipal and District Assemblies (MMDAs) coordinators, which would further organize data and transfer it up to the regional and from there to the national secretariat. The idea was that the information conveying through each of the organizational hierarchy would be of great benefit to the subordinator offices where the outcomes of the data can easily be resolved. The field officers generate the feedback reports concerning the existing framework, which is later passed on to the districts to initiate further analysis to better unpack the data obtained from the field. However, there were a lot of ambiguities with regards to whose responsibility it is in the various bridges within the feedback and reporting framework.

Moreover, the objective, thereafter, was to better understand the information conveying from the target beneficiaries in each stage of the reporting and monitoring framework and to make personnel in the various stages conversant with the monitoring activities. Likewise, the various stakeholders who include senior field officers, district coordinators, and local field staff, were positive about the result of the programme framework. Despite the positive perception about the existing framework, there were some contrary opinions concerning the practice of the framework in the later stage even among the programme implementers.

\subsubsection{The assumption of the feedback systems versus the reality on the grounds}

The field coordinators were meant to capture the quarterly information, accessing the progress or otherwise of the programme from the perspective of the youth or programme beneficiaries. Feedback systems in development are premised on three key concepts: 'participatory monitoring and evaluation, social accountability and customer/ beneficiaries satisfaction' (Jacobs et al., 2010, pp. 41). The capturing of field information regarding the programme coupled with other qualitative evaluations data from the beneficiaries on some of the programme's pitfalls and successes were also obtained on behalf with little or no involvement of the recipients. This defeats the first two concepts for lack of involvement and the failure on the part of beneficiaries to hold the programme implementers accountable.

The beneficiaries were made to assume that the processes were meant to pacify the implementers rather than the beneficiaries since they were written off in almost all the activities except for data collection. The assumption that greater participation of the target beneficiaries coupled with trained staff in the PM\&E process will serve as an empowerment tool was neglected to a large extent as revealed in the process analysis. Active involvement of all principal stakeholders in the monitoring and evaluation activities was assumed to be the best pathway to mitigate any of the challenges that may confront programme in the future saw a little attention.

The youth who participated in the process had diverse opinions regarding their involvement, while some felt the exercise was useful other stressed that it only serves the needs of the programme implementers and not the programme in its entirety. The evaluation activities, on one hand, were deemed helpful by the youth for its ability to lessen some of the anticipated pitfalls that may confront the target beneficiaries as well as the implementers. Moreover, the youth perceived that the goals of the initiatives could be better achieved if they are actively involved in the policy design stage right through implementation and ultimately the impact evaluation of the programme. Besides, the youth indicated that they were in a position to reveal some

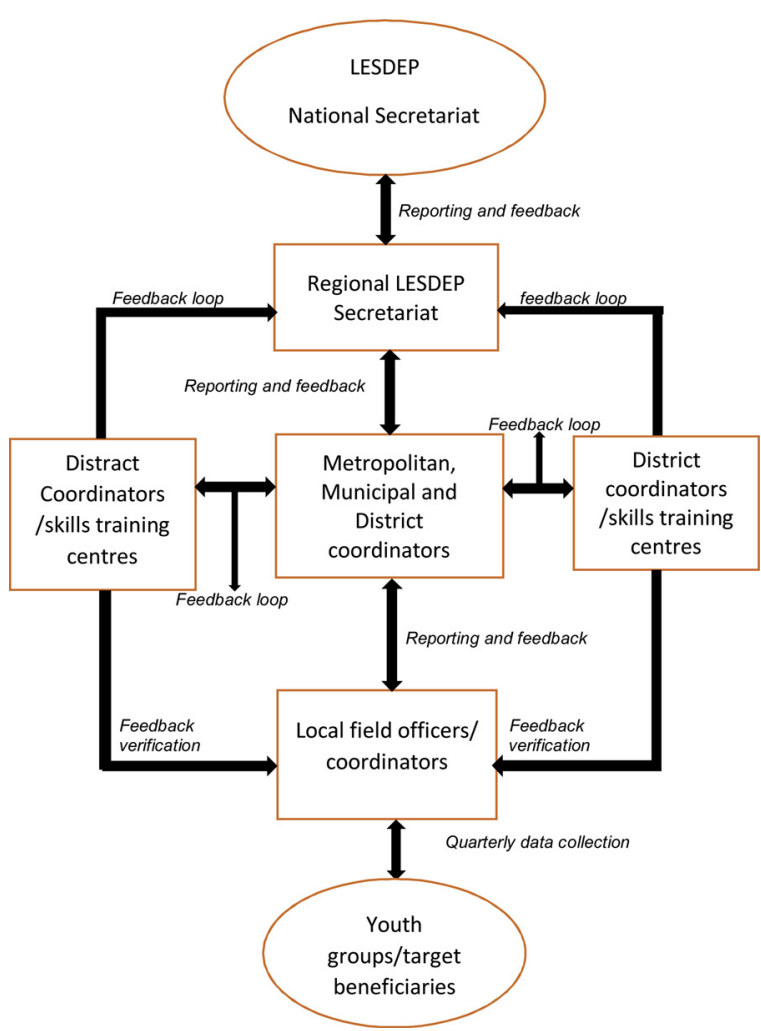

Fig. 1. The Ideal Organizational Management and Reporting Procedure for PM \&E.

Source: The author's construct from the flow of feedback and reporting inferred from the field study (assumed to be the operational framework from the various districts to the national secretariat).

of the achievements or otherwise of the initiative if they are made to actively involved in all the programme activities. However, others who were not involved or somewhat involved in the various activities perceived it to be doing the bidding of the programme implementers with no intended benefits.

The programme operational procedures and reporting for PM\&E has embedded a reverse reporting pattern from the various channels within the framework, from the national secretariat to regions, districts and eventually to the programme beneficiaries. However, the study revealed that there were no feedback loops from the national secretariat through the various bridges trickling down from the top to the programme beneficiaries after the determination of the PM\&E findings and decisions taken thereafter (see Fig. 1).

\subsection{Youth perceptions: participating in 'non-participatory'}

PM\&E was included in the operational plan of the programme. Following the setting up of programme beneficiaries after their training, the onus was on the government implementers, the regional and district coordinators to form a joint monitoring team to oversee the successes of the programme. Moreover, to perform an extensive progress evaluation of the programme, to gather input and identify the issues confronting the youth, the regional staff, district coordinators, and provider agencies were to coordinate these processes. Implementers identified the need for a consultative process between district or regional coordinators and youth to provide appropriate feedback and reports to the national secretariat.

The goal was to incorporate the various concerns emanating from the local level especially from the youth for the re-shaping of the programme activities as well as the underlying mission or objectives of the initiative. Evaluators feedback information in any evaluation activities 
is essential for both programme implementers and target beneficiaries. The dissemination of information from the programme office/field evaluators to target beneficiaries is of great importance in participatory monitoring and evaluation activities. Learning and knowledge are some of the key principles or by-products in any evaluation activities. However, inference from the organizational reporting and evaluation framework revealed that there was no feedback loop from the national secretariat to the programme beneficiaries.

Ideally, PM\&E must involve all stakeholders from the initial design through identifying of the data needed for decision making after the PM \&E findings, however, due to the tedious nature of PM\&E, some scholars have suggested that at least key stakeholders must have representatives to partake in all the processes (Rebien, 1996). Contrary to this assumption, LESDEP programme beneficiaries (youth) who are one of the key stakeholders were excluded from the processes except for data collection. Thus, in theory, the form and nature of the evaluation processes epitomise PM\&E, yet, in practice, the system failed to incorporate beneficiaries (youth) in the existing progress evaluation system. A staff member stated that:

The beneficiaries have always been with us throughout these processes but they were not involved in the designing of the instrument among others, I mean the technicalities of the whole processes but to some extent they were with us, they were involved in some way, and they were respondents for most of the data gathered (R1 LESDEP Staff, November 9, 2016).

The programme PM\&E approach, however, disguised some essential conceptual issues underpinning the term 'stakeholder'. Despite the programme operational requirement to involve the various stakeholders in all the stages, the notion of a 'stakeholder' was rhetorical and vague in that, programme target beneficiaries were left out in the stakeholder evaluation committee. Besides data collection, the designation of the existing monitoring and evaluation structure, the selection of indicators to be used, data analysis, and decision making after the PM\& E were mostly decided by the programme implementers to the detriment of the youth. Thus, the youth felt side-lined for the minimal involvement at the various stages in the process, although the majority expressed their willingness to participate if granted the opportunity. Consequently, inferences from the above-quoted statement from the field study revealed that the scope of the PM\&E was narrowed, which suffers greatly to be called participatory in nature and character.

\subsubsection{Towards a Re-placed of illusive participation and power disparities}

The level at which the youth were made to participate in the existing activities confirm a disparity of power between programme implementers and beneficiaries (youth), thus the need for a participatory process which goes beyond the narrow conception demonstrated by the implementers. The challenge, however, for programme implementers is to accentuate the 'limitlessness' of target beneficiaries by developing a collaborative system that places some level of significance on the need for young people involved in the various stages in the existing PM\&E. This must take place in an environment where there is greater emphasis on knowledge sharing, learning, skills, and capacity building as well as empowerment of all stakeholders including project recipients (youth).

However, this requires some financial and material resources which were some of the hiccups in the programme implementation. Inadequate financial resources compelled implementers to allocate resources where they were deemed important, such as the provision of set-up funds to the detriment of the progress evaluation. Weiss (1973) argued that power and politics in every organisation have the potential to shape the evaluation culture, practices and outcomes and this was revealed in during the field study. That notwithstanding, Cornwall (2008) stressed that the involvement of youth in PM\&E may serve as a source of power, control or empowerment. Thus, the recognition of the existing power imbalance will be central to the formulation of the PM\& E process that is based on devolution or redistribution of power.
The process analysis of the field study revealed that the programme implementers failed to involve the youth in the pertinent stages in the PM\&E activities beside data collection. The primary stakeholders were left out in all except data collection stage where they were made to serves as mere respondents. There is more to participatory monitoring and evaluation than ticking a box and responding to pre-coded questions. The study revealed that programme implementers were more interested in providing apprenticeship job for the youth rather than their involvement in the programme design, implementation and evaluation activities. Moreover, the youth were perceived to be mere 'beneficiary/beneficiaries' but not as a primary stakeholder which presumes that there is a great power differential between government programme implementers and the youth.

Youth intervention programmes largely come across as effective ways to reduce unemployment among the economically active population, yet, the numbers of such programmes 'died before they were born'. The study revealed that the end goal of the intervention programme was project/programme sustainability, however, that was not realized as a result of the poor process evaluation approach adopted by the programme implementers. Holte-McKenzie et al. (2006) in their study in Kenya argued that this could be achieved if the various stakeholders (including the youth) are made to actively participate in all the processes (from the design stage through implementation to monitoring and evaluation).

The analysis of the field data revealed that the national, regional and district office and field implementers tend to own the initiatives to the detriment of the youth. However, a participatory approach which seeks to enrol all the stakeholders from the policy design stage through to implementation, monitoring and impact evaluation stages has the potential of ensuring programme sustainability. The PM\&E approach should seek to appreciate the interest as well as the holistic involvement of all stakeholders at the various stages in the project/programme. There must be a deliberate creation of a conducive environment that allows stakeholders to discuss the pros and cons of the programme.

The primary stakeholders (youth) will be motivated to have a sense of ownership towards the programme if they are allowed to actively participate in all the activities. Recipients participating in the data capturing and analysis of the data thereafter could be of great benefit for them and the programme at large. However, within this framework, the youth involvement in the various stages of the PM\&E activities was minimally articulated, while greater emphasis was offered to coordinators regarding the capturing of initial information, analysing it thereafter, and reporting feedbacks as well as other qualitative information. The case study reveals that in a multi-stakeholder setting, devolution of responsibilities and adherence to those principles coupled with some key elements of the participatory process tends to become a challenge when the "common vision" is from the implementer. The nature of power differentials among the stakeholders affected the various feedback loops hence the varying perspectives regarding the participatory process.

\section{Lessons learned}

The extensive literature on participatory development especially in the context of social intervention policies or programmes often portrays participatory monitoring and evaluation as a way of knowledge sharing, learning, and empowerment of the primary stakeholders. The goal of such system is what Cousins and Whitmore (1998) term "pragmatic participatory evaluation" (p. 8) which seeks to empower the voiceless for them to actively participate in any social or economic development programme that aimed to enhance their wellbeing. A process which has also been termed as "transformative participatory evaluation" (Plottu \& Plottu, 2011, p. 806).

Both concepts aim to ensure some level of ownership, learning, empowerment, and sharing of ideas for change, however, in the case of LESDEP, the PM\&E approach was far from providing such remedies as a 
result of the varying perspectives and interest of the youth and implementers coupled with power disparities. There was a desire on the part of programme officials to grant the youth some degree of ownership and accountability, however, that was affected by the power disparities between the two (implementers and youth). Although the programme implementers intended to involve the youth in the PM\&E activities, some of the youth set their eyes on the ultimate goal (provision of jobs) which was in direct conflict with the progress evaluation processes anticipated by LESDEP.

While some of the youth hastened to viewed the various process as beneficial because it gave them some degree of power to control, negotiate and influence the various activities from the commencement of the programme to the impact evaluation, others perceived it as blatant patronisation on the part of the implementers to tick the various boxes set by the programme. Although this entrenched interest and perspective on the part of the youth were seemingly basic, however, the result was that some of the youth perceived the PM\&E as work that needs to be done by the programme officials. Generally, quite a number of the youth were not interested in altering the implementer's perspective regarding the participatory process, rather, they choose to concentrate on the material and financial resources promised by the government (implementer). This is in contrast of Holte-McKenzie et al. (2006) study in Kenya where the target beneficiaries (youth) were interested in the various activities and were gradually empowered to participate in PM\& E processes over time.

The readiness assessment and the design of PM\&E should be critically looked at before the implementation of a particular intervention programme. The organizational capacity is of equally important as the design of the PM\&E framework. The goals and objectives of the target beneficiaries are of particular importance even though they might differ greatly from the goals and objectives of the programme. The recognition of financial and material resources for both beneficiaries and programme implementers. Any PM\&E system should consider aligning and scrutinizing the goals of the target beneficiaries and that of the programme implementers. Entrenched goals and interests of the various stakeholders have the potential to influence the PM\&E activities negatively.

Indeed, there is the need to anticipate some cost and benefits of the PM\&E system and how all the stakeholders could play their part to minimise cost while maximising the benefits. It is also worth noting that such a system should be premised on enhancing the well-being of the marginalized stakeholder. PM\&E system is more efficient and effective when all the stakeholders already have some degree of expectation and drive, besides, the needed skills and level of literacy. Judging from the nature, form and the perceived success of the PM\&E system, LESDEP was not too far from what was envisioned.

Moreover, a PM\&E system requires human, material and financial resources to implement on the part of the programme implementers and target beneficiaries. However, how these resources are allocated, 'who gets what, when and how and perhaps who pays for it', always becomes a political decision on the part of programme implementers and recipient due to varying perspectives. The inadequate programme resources for the implementation of the progress evaluation system and the underlying political nature in shaping the distribution of those resources concerned the youth the most. In the design of PM\&E, it is also necessary to consider the power disparities or nexuses between government programme implementers, field or office staffs, and target beneficiaries. For instance, if the PM\&E systems aimed to balance the power relations between programme implementers and the youth, then, they should have been involved in each stage of the processes from design to implementation. This has the potential to curbing elite manipulation of the system to fulfil their interest.

Consequently, the majority of the youth interviewed explained that PM\&E was a way of fulfilling the political interest of the implementers. This viewpoint could not be far from been wrong since the cost of PM\&E design and implementation were cited by the programme as a key challenge. LESDEP management addressed this by selecting a few of the youth to serve as representatives, participation in an attempt to cut cost but ensure there is some level ownership. However, the representatives were to be selected by the youth or recipient of the programme and not the programme implementers as it was the case of Holte-McKenzie et al. (2006) study in Kenya. Youth empowerment could be achieved when they are allowed to nominate the colleagues to represent them in the PM\&E.

Finally, all of the above key lessons inferred from the case study indicates the need to fulfil some preconditions to ensure PM\&E. A readiness assessment is a prerequisite for good participatory monitoring and evaluation. Capacity building on the part of target beneficiaries and programme implementers, as well as the provision of material and financial resources, are relevant for efficient implementation. The introduction of PM\&E in any social intervention programme must consider both the perspectives and benefits of programme beneficiaries from a rational standpoint. Programme beneficiaries must be in the know, the cost and benefit analysis of the PM\&E system, what will programme implementer and recipients gain or lose? How are gains and losses likely to affect the various stakeholders and how can it be distributed amongst these stakeholders? While the case of LESDEP might have not been deliberate in selecting the few literate youths to participate in the participatory processes, it gave them the power to influence, control and negotiate to the detriment of the majority. The likelihood that it could provoke some level of uncertainties, especially among the illiterate youth, is very high, which could also affect the PM \&E system.

\section{Conclusion}

Youth intervention programmes in Ghana are mostly manned by different government ministries, department, agencies and private providers. This paper has shown how power disparity, coupled with the varying interests of implementers and target beneficiaries of the programme impacted on the PM\&E process. The impact of the PM\&E was not properly sustained largely because of the power discrepancies between programme implementers, district coordinators, and beneficiaries (youth). It served as some of the key drawbacks within the PM $\& \mathrm{E}$ activities from the national office to the local beneficiaries.

The programme reporting and feedback information from the districts delimited the active participation of beneficiaries. However, the district coordinators make some efforts to engage the youth in the process. The participatory process within this programme was heavily reliant on the "top-down" approach with its bureaucratic tendencies from the secretariat to the districts. The process was erroneously perceived by the youth as something for the expert class and failed to partake in the participatory activities. The differences perspectives and priorities among the stakeholders (beneficiaries interested in the apprenticeship job and implementers focused on the organizational management of the programme) within the programme impacted on the already existing disparities.

These power disparities were largely not recognized by the government programme implementers which was a concern for the youth. The programme participatory framework was designed to grant those who were deemed dormant in the process some degree of power to be able to influence and shape the outcome of the programme. However, this so-called empowerment was given to a few selected literate beneficiaries to the detriment of the majority. Power is, therefore, granted to the programme staff officials and expert professional to conduct the "participatory process". Moreover, the ultimate goal of the PM\&E is crucial, therefore, it is necessary that programme implementers partners with beneficiaries in the participatory process. It is beneficial that implementers, government or donor agencies allocate funds for monitoring and evaluation embedded in a participatory approach. 


\section{References}

Ackermann, L., Feeny, T., Hart, J., \& Newman, J. (2003). Understanding and evaluating children's participation: A review of contemporary literature. London: Plan Ltd and Plan International (UK).

Amankrah, J., \& Burggraaff, E. (2012). Mapping Study Ghana: Needs and Priorities in Demand Driven Vocational Training of Youth. [Online]. Available at: http://schoklandtvet.pbworks.com/w/file/fetch/62156048/Mapping\%20Study\%20Ghana \%202012\%20E.\%20Burggraaff\%20-\%20J.\%20Amankrah.pdf. Retrieved June 3, 2016..

Antonio, D. (2001). The challenges for Africa: A culture of peace, good governance and people-centered development. Asia Pacific Review, 8(1), 63-74.

Ataov, A., \& Haider, J. (2006). From participation to empowerment: Critical reflections on a participatory action research project with street children in Turkey. Children Youth and Environments, 16(2), 127-152.

Arnstein, S. (1967). A ladder of citizen participation. Journal of the American Planning Association, 35(4), 216-224.

Boadu, E. S., \& Ile, I. (2017). Rethinking participation in monitoring and evaluation. Beneficiaries' perspectives from the Local Enterprises and Skills Development Programme (LESDEP) in Ghana. Loyola Journal of Social Sciences, 31(2), 209-227.

Boadu, E. S., \& Ile, I. (2018). The politics of youth participation in social intervention programmes in Ghana: Implications for participatory monitoring and evaluation (PM \&E). Journal of Reviews on Global Economics, 7, 913-925.

Cahill, C. (2007). Doing research with young people: Participatory research and the rituals of collective work. Children's Geographies, 5(3), 297-331.

Checkoway, B. N., \& Gutierrez, L. M. (2006). Youth participation and community change. Journal of community practice, 14, 1-91.

Chitukutuku, E. (2014). Things Youth in Africa consider important or valuable and how they inform youth participation in Electoral and Governance Processes. Discussion Paper for the 2014 Mandela Institute for Development Studies (MINDS) Annual Youth Dialogue in Elections and Governance.

Chouinard, J. A., \& Cousins, J. B. (2013). Participatory evaluation for development: Examining research-based knowledge from within the African context. African Evaluation Journal, 1(1), 9.

Corbin, J., \& Strauss, A. (2008). Basics of qualitative research: Techniques and procedures for developing grounded theory. Los Angeles: Sage Publications.

Cornwall, A. (2008). Unpacking Participation": Models, meanings, and practices. Community Development Journal, 43(3), 269-283.

Cousins, J. B., \& Whitmore, E. (1998). Framing participatory development. New Directions for Evaluation, 80, 5-23.

Department for International Development (DFID) (2010). Youth participation in development. A guide for development agencies and policymakers. Available here: Retrieved June 6, 2016DFID-CSO Youth Working Grouphttp://www.youthpolicy.org/ wpcontent/uploads/library/2010_Youth_Participation_in_Development_Guide_Eng. pdf.

Estrella, M. (2000). Learning from change. Learning from change: Issues and experiences in participatory monitoring and evaluation. 1-14.

Guijt, I. (2014). Participatory approaches: Methodological Briefs-Impact evaluation no.5 (No. innpub750).

Hilhorst, T., \& Guijt, I. (2006). Participatory monitoring and evaluation: A process to support governance and empowerment at the local level. Guidance paper. The Netherlands: Royal Tropical Institute (KIT).

Hogh-Jensen, H., Oelofse, M., \& Egelyng, H. (2010). New challenges in underprivileged regions call for people-centered research for development. Society and Natural Resources, 23(9), 908-915.

Holte-McKenzie, M., Forde, S., \& Theobald, S. (2006). Development of a participatory monitoring and evaluation strategy. Evaluation and Program Planning. Vol. 29(4), 365-376.

Jacobs, A., Barnett, C., \& Ponsford, R. (2010). Three approaches to monitoring: Feedback systems, participatory monitoring and evaluation and logical frameworks. IDS Bulletin, 41(6), 36-44.

Lansdown, G. (2001). Promoting children's participation in democratic decision-making. Innocenti insight. Piazza SS. Annunziata, 12, 50122 Florence, Italy: UNICEF Innocenti Research Centre.

Local Enterprise and Skills Development Programme (LESDEP) (2016). Ghana, 2016. http://www.lesdepgh.org Retrieved from their webpage on 25th August.

Masters, Z., Macintosh, A., \& Smith, E. (2004). Young people and e-democracy: Creating a culture of participation. International Conference on Electronic Government. Berlin, Heidelberg: Springer15-22.

Mosse, D. (2005). Cultivating development: An ethnography of aid policy and practice (Anthropology, culture and society). London, UK: Pluto Press.

Nurick, R., \& Johnson, V. (2001). Putting child rights and participatory monitoring and evaluation with children into practice: Some examples in Indonesia, Nepal, south Africa and the UK. PLA Notes, 42, 39-44.

Parfitt, T. (2004). The ambiguity of participation: A qualified defense of participatory development. Third World Quarterly, 25(3), 537-556.

Patton, M. Q. (2008). Utilization-focused evaluation (4th edn.). Thousand Oaks, CA: Sage.

Plottu, B., \& Plottu, E. (2011). Participatory evaluation: The virtues for public governance, the constraints on implementation. Group Decision and Negotiation, 20(6), $805-824$.

Pimbert, M., \& Pretty, J. N. (1995). Parks, people and professionals. Geneva: United Nations Research Institute for Social Development.

Rebien, C. C. (1996). Participatory Evaluation of Development Assistance: Dealing with Power and Facilitative Learning. Evaluation, 2(2), 151-172.

Shafik, N. M. (2010). Youth participation in development a guide for development agencies and policy makers. Published by the DFID-CSO Youth Working Group. DFID-CSO Youth Working Group March 2010.

Simon, G. (2014). In Tunisia: Breaking the barriers to youth inclusion. 1818 H Street, NW Washington, DC 20433, USA: The International Bank for Reconstruction and Development / The World Bank Group.

Sabo, K. (2001). The benefits of participatory evaluation for children and youth. PLA Notes \#42. London: IIED48-51.

Shier, H. (2001). Pathways to participation: Openings, opportunities, and obligations: A new model for enhancing children's participation in decision-making, in line with article 12.1 of the United Nations Convention on the Rights of the Child. Children \& Society, 15(2), 107-117.

Tisdall, K. E. (2008). Is the honeymoon over? Children and young people's participation in public decision-making. The International Journal of Children's Rights, 16(3).

Turner, A. (2007). Bottom-up community development: Reality or rhetoric? The example of the Kingsmead Kabin in East London. Community Development Journal, 44(2), $230-247$.

Van-Beers, H. (2002). Children's Participation: Experiences in capacity building and training. Save the Children. Sweden: Stockholm.

Weiss, C. (1973). Where politics and evaluation research meet. Evaluation, 1(3), 37-45.

World Bank (2014). Tunisia - Breaking the barriers to youth inclusion (English). Retrieved August 15, 2016Washington, DC: World Bank Group. http://documents.worldbank. org/curated/en/753151468312307987/Tunisia-Breaking-the-barriers-to-youthinclusion.

Zeldin, S., Petrokubi, J., \& MacNeil, C. (2008). Youth-adult partnerships in decision making: Disseminating and implementing an innovative idea into established organizations and communities. American Journal of Community Psychology, 41(3-4), 262-277.

Zeldin, S., McDaniel, A. K., Topitzes, D., \& Calvert, M. (2000). Youth in Decision-Making: A study on the impacts of youth on adults and organizations. Chevy Chase, MD: 202 National 4-H Council. www.atthetable.org.

Zurba, M., \& Trimble, M. (2014). Youth as the inheritors of collaboration: Crises and factors that influence participation of the next generation in natural resource management. Environmental Science \& Policy, 42, 78-87.

Professor Isioma Ile is a professor at the School of Government (SOG), Economic Management Faculty (EMS), University of the Western Cape (UWC), Cape Town, South Africa. She holds a B. ED in Education and Political Science (honours) from the University of Ibadan, Rivers State College of Education, Port Harcourt Nigeria. A joint master's degree in Public Administration (MPA) from the University of the North \& University of Pretoria (UP) and a PhD in Public Administration from UP, South Africa. She is a professor of Public Sector Planning, Monitoring and Evaluation with a major emphasis on participatory monitoring and evaluation. Ile has a broad range of research projects/ interest arears which includes but not limited to public sector planning, project planning and monitoring and evaluation. She is currently pursuing a research project that seeks to juxtapose mainstream and indigenous social policies and governance systems in Africa. The pursuit of study is to unpack the monitoring and evaluation viewpoints in both streams.

Mr. Evans Sakyi Boadu studied in Accra at the University of Ghana (UG) where he successfully completed two degrees: B.A. in Political Science and M.A. in Population Studies. As a scholar he continued for another degree in graduate studies at University of the Western Cape (UWC), Cape Town, South Africa where he obtained Masters in Public Administration (MPA). Mr. Boadu is currently pursuing Ph.D. in Public Administration at (UWC). I am focusing my studies on participatory monitoring and evaluation (PM\&E) in social intervention programmes in Africa by comparing social or entrepreneurial programmes in mainstream government and indigenous governance systems in Africa. Thus, I am very much interested in social policy/intervention research and project implementation and monitoring and evaluation. 